\title{
WIBITY NOTICE
}

A major purpose of the Technical Information Center is to provide the broadest dissemination possible of information contained in DOE's Research and Development Reports to business, industry, the academic community, and federal, state and local governments.

Although a small portion of this report is not reproducible, it is being made available to expedite the availability of information on the research discussed herein. 


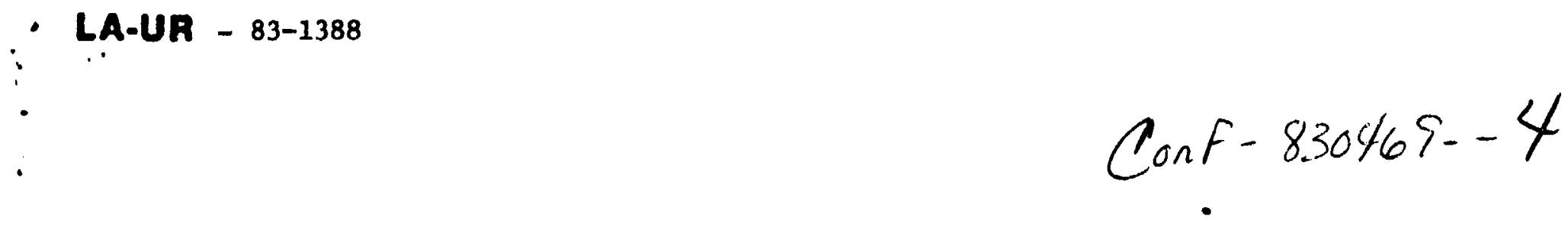

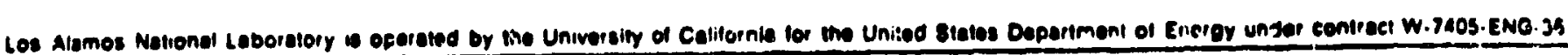

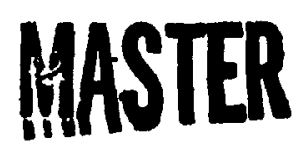

T,A-UR- $-83-1388$

nE83 012670

TITLE: DYNAMICAL FUSTON THEESHOLDS IN MACROSCOPIC AND MICROSCOPIC THEORIES

AUTHOA(S):

Thomas R. Davies, Physics Division, Oak Ridge National Laboratory old J(ohr.) Slerk, T-9

$J$ (ames) Rayford N1x, T-9

SUBMITTED IJ:

Proceedings of Conference on Nuclear Physics with Heavy Ions

Stony Brook, New York, Apr11 14-16, 1983

\section{DISCLAIMER}

This report was prepared as an nocount of motk aponsored by an agenoy of the United States Covernment. Nolther the United States Government nor any agenoy thereof, nor any of thelr

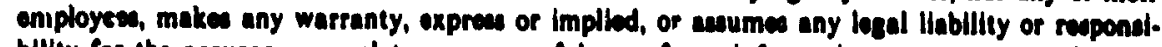

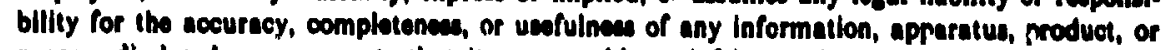

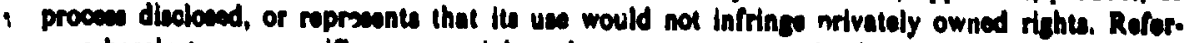

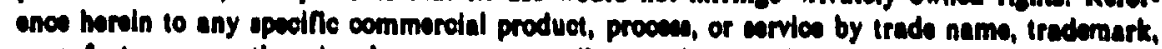
manufacturer, of otherwien doen not necescarily conatliute of imply ite endorcoment, reenm. niendation, of favoring by the United State Cowornment of any egenoy therenf The vow

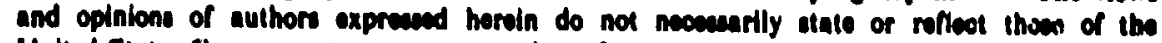
United Stete Cowornmont or any agency thereof. 
DYNAMICAL FUSION THRESHOLDS IN MACROSCOPIC AND MICROSCOPIC THEORIES

R. Thomas R. Davies

Phyo1:s Div1s1on, Oak R1dge Natlonal Laboratory

Oak R1dge, Tennessee 37830

Arnold J. Sierk

Theoretical Division, Los Alamos National Laboratory

Los Alamos, New Mexico 87545

J. Rayford Nix

Theoretical Division, Los Alamcs National Laboratory

Los Alamos, New Mexico 87545

\author{
to be publiahed in \\ Proceedinge of Conference on \\ Nuslear Phyalcs with Heavy Ions \\ Stony Brosk, New York
}

Apr11 14-16, 1983

\author{
Uv exenolence of inis eptlele, the \\ dublisher or reetplent eeknowiodges \\ the U.e. Oevernment'itight to \\ retein e nonevelueive, pyally liee \\ licence in and to onv copyriont \\ eoverine the articie.
}


DYNAMICAL FUSION THRESHOLDS IN MACROSCOPIC AND MICROSCOPIC THEORIES *

K. THOMAS R. DAVIES

Physics Division, Oak Ridge National Laboratory

Oak Ridge, Tennessee 37830

ARNOLD J. SIERK

Theoretical Division, Los Alamos National Laboratory

Los Alamos, New Mexico 87545

J. RAYFORD ITX

Theoretical Division, Los Alamos National Laboratory

Lo8 Alamos, New Mexico 87545

Macroscop1c and microscoplc results deoonstrating the existance of dynamical fision thresholds are presented. For wacroscoplc theorles, it 1s shown that the extrapush dynamica 18 senaltive to sowe detalle of the models used, e.g. the shape parametrization and the type of viscosity. The dependence of the effect upon the charge and engular womentum of the oystem 18 aiso -tudied. Calculated macroscoplc results for massaymmetrle syeteme are compared to experimental missasymetric results by use of a tentatlve scaling procedure, which takes into account both the entrancechannel and the saddle-point reglone of configuration apace. Two types of dynamlcal fusion thresholds occur In TWHF otudies: (1) the microscopic analugue of the macroscoplc extra push threshold, and (2) the relatively hlgh energy at which the TDHF angular momentum window opens. Both of these microscople thresholds are found to be very sensitive to the cholce of the effective two-body interaction.

"Research supported by the U.S. Department of Energy under a contract with the University of California and Contract W-7405-eng-26 with the Union Carbide Corporation. 
K.T.R. DAVIES, A.J. SIERK and J.R. NIX

1. INTRODUCTION

Since a wide variety of theories and models have been developed in order to understand heavy-ion reactions, it is interesting to explore the relationships between different theoret1cal approaches. While formal connectlone between different methods are usually obscure, it 1s poss $\leq b 1$ fe for two theories to give quite consistent agreement - qual1taLively if not quantitatively - regarding a particular type of reaction. In this paper we shall demonstrate that two quite different theories qualitatively predict very simflar behavior for heavy-ion fusion. Specifically, we shall discuss dynantcal fusion thresholds, which are predicted in vartous macroscop1c models ${ }^{-5}$ and also in microscopic TDHF theory. 6-10

Th1s paper 18 structured as follows. In Section 2 we introduce the concept of a dynamical fusion threshold. Section 3 presents recent wacroscoplc studies 5 which demorstrate the sensitivity of the extrd-push threshold to various detai.1s of the model, particularly the viscosity mechan1am. Then, in Section 4 we discuse the TDHF fusion thresholds, which Include both the extra-push threshold and the angular mowentum window, and we show the sensitivity of these th-esholds to changes in the effective two-body interact1on.911 Flnally, Saction 5 glves a brief summary of our resulte.

2. DYNAMICAL FUSION THRESHOLDS

The concept of an additional energy for fusion, or an extra push, 1-5 1s 1llustrated schematically in F1g. 1. In shis f1gure, $E_{B}$ is the maximum value of the internction berrier for one-dimensional (radial) motion in the entrance channel, 
DYNAMICAL FUSION THRESHOLDS

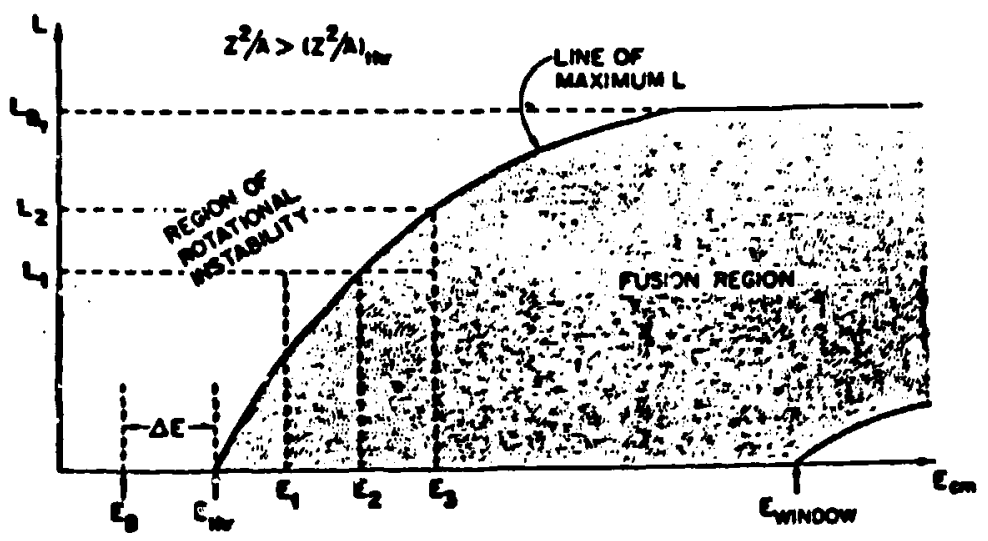

FIGURE I Typical fusion region in the CM energy, angular momentum plane. The figure contains features occurring in both macroscoplc and microscoplc studies. The angular momentum $L_{B_{f}}$ is the angular momentum for which the fusion barrier vanishes.

ard the threshold $E_{t h r}$ is the minimum energy for which one obtains fusion for head-on collisions. Now for light systems, If subbartier fuston is neglected, thess two energies are 1dent1cul. Then if the charge on the systum is increased, the tliresinold energy increases since wore energy is required for fusion. However, $E_{B}$ also increases with charge so that $E_{\text {thr }}$ and $E_{B}$ coincide unt1l we reach some critical fissility designated by $\left(Z^{2} / A\right)_{t h r}$, after which $E_{\text {thr }}$ increases faster than $E_{B}$. In th1s plcture $22 / A>(2 / A)$ thr and $\Delta E-E_{t h r}-E_{B}$ is the additional energy above the barrier required to give fusion for head-on collistons.

We note that Fig. I showe a zelatively high-enargy threshold $E_{\text {window }}$ where fusion abruptly disappears for $L=$ 0 . This 1s the TDHF angular momentum window.6,9 Th1. tlireshold is also of dynamical origin, but it is completely different from the extra-push threshold shown at the lower energy. It 1s intimately associated with the transparency inherent in the mean-field approximation, and its existence 
K.T.R. DAVIES, A.J. SIERK and J.R. NIX

has not been verified experimentally. 11

\section{MACROSCOPIC CALCULATIONS}

One of the main lessons that we have learned about fiston behav10- 1 s that, as the angular momentum or the charge on the system Increases, It becomes wore difficult to describe the dynamlcs by simple one-dimensional models.1-5 Thus, macroscropic calculations should ideally be dane using general set of collective coordinates, and $1 t$ is convenient to project from this mitidimensional configuration space several simple coordinates which have special physical significance. For our studies, 5 these projected coordinates are denoted by $r$, which gives the distance between the mass centers of the lons, and $\sigma$, which is 2 measure of fragment elongation (or necking). The spectfic model that we use is an axtally symetric shape consisting of smoothly joined portions of three quadratic surfaces of revolution. 12 The coordinates $I$ and $\sigma$ are then defined in texms of moments of the nuclesr shape.5,13 For mas-symetrtc reactions, I and $\sigma$ are given by

$$
\begin{aligned}
& r=2\langle z\rangle, \\
& 0=2\left[\left\langle z^{2}\right\rangle-\langle z\rangle^{2}\right]^{1 / 2,}
\end{aligned}
$$

where 2 1s measured along the symetry axis and the angular bracket denotes an average over the half volume to the right of the midplane of the body.

The dynamical trajectortes are obtalned by solving the claselcal Hamition's equations of wotion, which have been generalized to include viscosicy 13:

$$
\dot{q}_{1}=\frac{H_{1}}{\partial p_{1}} \quad, \quad 1-1,2, \ldots N,
$$


DYNAMICAL FUSION THRESHOLDS

$$
\dot{p}_{1}=-\frac{\partial H}{\partial q_{1}}-\frac{\partial F}{\partial q_{1}}, \quad 1=1,2, \ldots N,
$$

where $q_{1}$ and $p_{1}$ are a collective coordinate and Its conjugate mumentum and

$$
\mathbf{H}=\mathbf{T}+\mathbf{V} \text {. }
$$

The potential energy $V 1 s$ the sum of the Coulomb electrostatic energy and a nuclear macroscoplc energy

$$
V(q)=v_{\text {coul }}(q)+v_{\text {nucl }}(q) \text {. }
$$

while $T$ is the collectlve kinetic energy and $F$ is the Raylelgh dissipation function.

In Fig. 2 we display a potential-energy contour map for

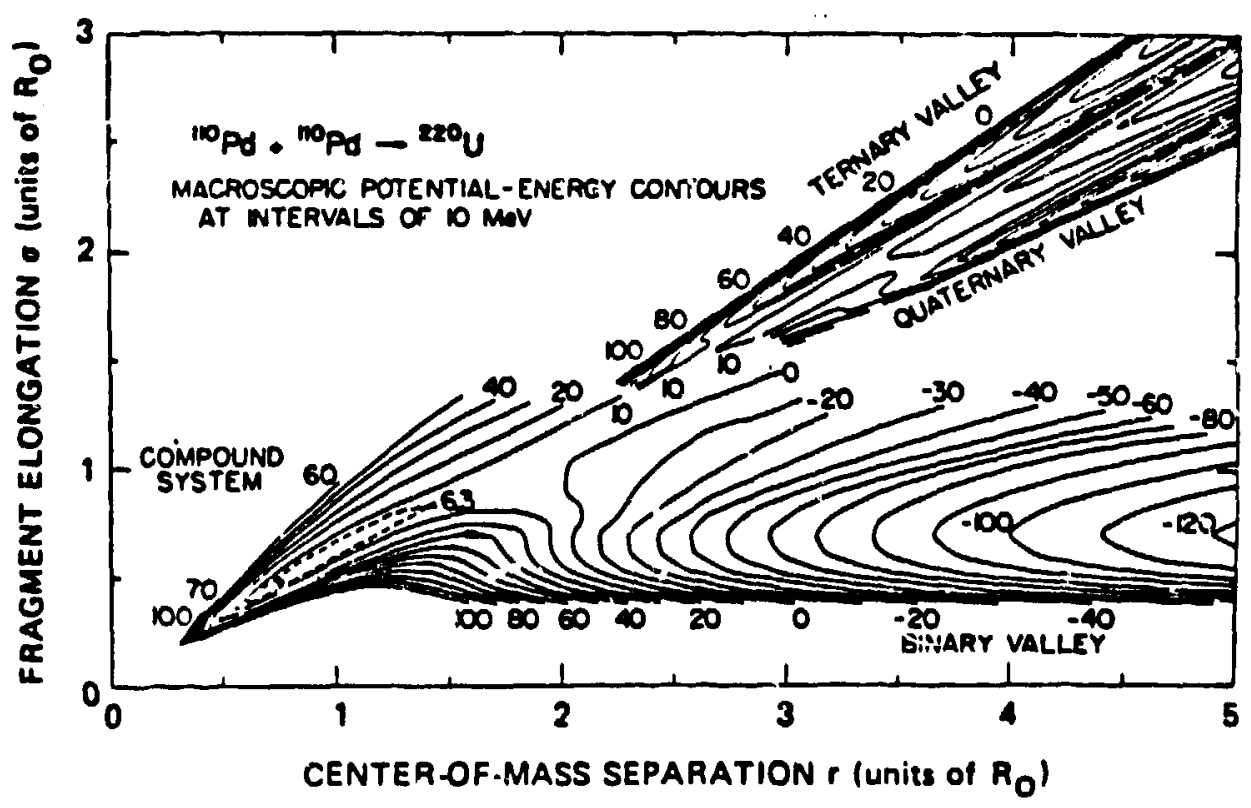

FIGURE 2 Potential-energy contoura, in units of MeV, for the reaction $110_{\mathrm{Pd}}+110_{\mathrm{Pd}} \rightarrow 220_{\mathrm{U}}$, calculated with a bingle-Yukawa macrosceple model. 14 The location of the sphere 18 given by the solid point, and the location of two touching spheres is given by two alfacent solld pointe. 
K.T.R. DAVIES, A.J. SIERK and J.R. NIX

the head-on coll1s1on of 110Pd + 110Pd $\rightarrow 220 \mathrm{U}$. In1t1ally, the two separated spherical $110 \mathrm{Pd}$ nuclel move up the binary valley, near the bottom of the figure, and come into hard contact at the point indicated by the two adjacent circles. Th1s point is slightly inside the maximuw in the onedimensional interaction barrier, but is on the side of $a$ steef hill with respect to fragment elongation. The saddle point of the combined system is located at the intersection of the dashed 6.3-MeV contours. The criterion that we have adopted for compound-nuclets formation is that the dynamical trajectory passea to the left of the saddle, so that the system becomes trapped in the potential-energy hollow surrounding the sphere. If the trajectcry passes to the right of the saddle point, the system reseparates in a deepinelastic reaction.

Figure 3 illustrates typical dynamical trajectorios in the $r, \sigma$ plane for various values of $\Delta E$, which is the difference between the $M$ energy and the marimum in the onedimensional interaction barrfer. This figure shows that as the bombarding energy lncreases, the trajectorles are displaced to the left, giving rise to wore compressed shaper, the trajectoriec for $\Delta E=0.5$ and $20 \mathrm{MrV}$ do not fuse, while $\Delta E$ - $90 \mathrm{MeV}$ is the threshold value, or mirimum $\Delta E$ required for fusion, since 1ts trajectory fust passes through the saddle polnt of the comblined system.

In Fig. \& we compare dynamical trajectorles for five different types of dissipation: zero dissipation, urdinary two-body v13cosizy with a viscosity coefficlent of .02 TP, 13,17 one-body wall-formula dis81pation, $18^{-19}$ onebody wall-and-window dissipation, $17^{-19}$ and pure window dissipation. The dynamical pathe for no dissipation and two-body viscosicy prefer changes in separation $r$ rather 
DYNAMICAL FUSION THRESHOLDS

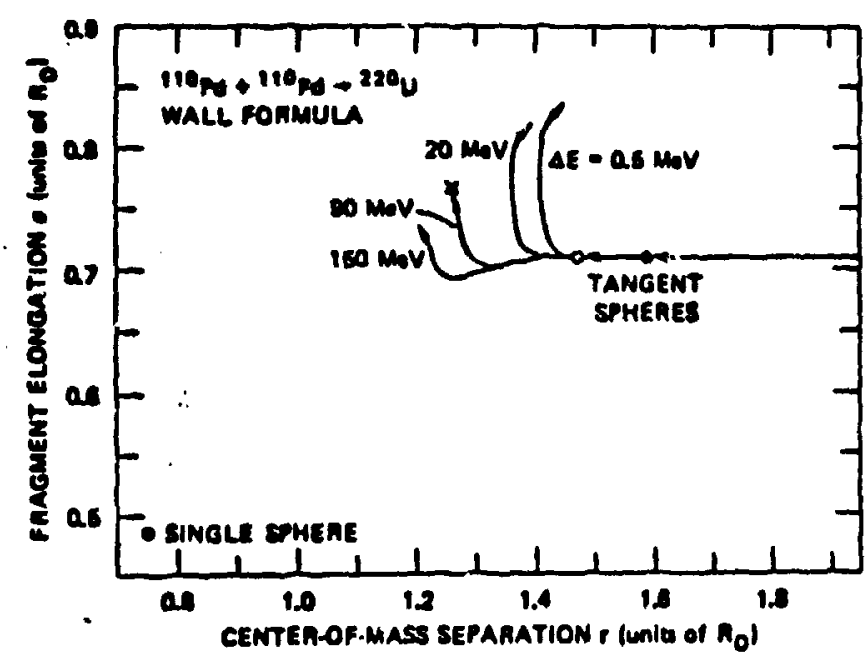

FIGURE 3 Effect of bombarding energy on dynamical trajectorles in the $r-\sigma$ plane for the head-on coll1sion, $110 \mathrm{Pd}+110 \mathrm{Pd} \rightarrow 220 \mathrm{U}$, calculated for wall-formula dissipation. Here, and in Figs. 4-6, the saddle-point configuration for the combined system is ind cated by a cross ( $x)$, and the nuclear macroscopic energy is the Yukawa-plus exponent1al mode1. 15,16

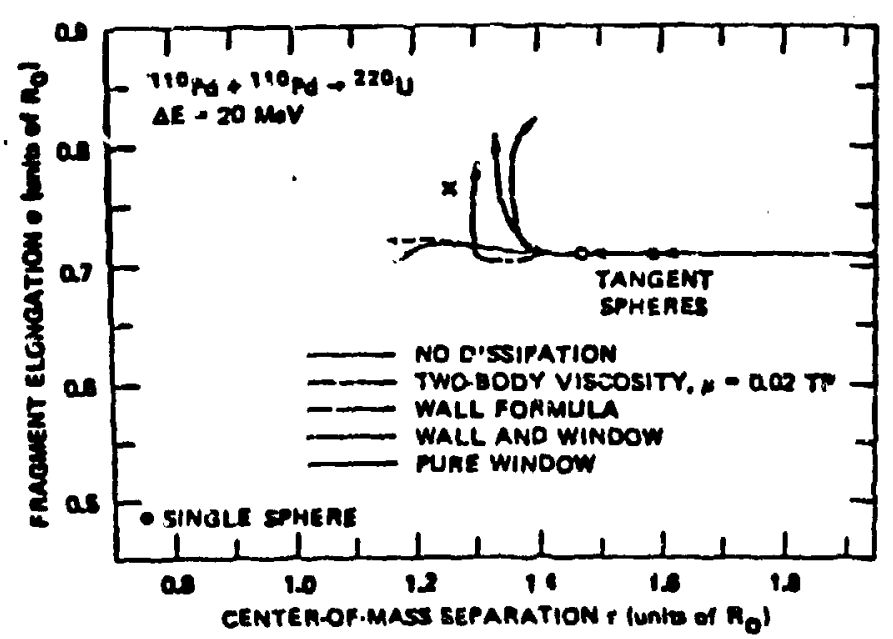

FIGURE 4 Effect of dissipation on dynamicel trafectorles in the $5 \cdots$ plane for the reaction $110 \mathrm{Pd}+110_{\mathrm{Pd}}$ $+220 \mathrm{~V}$ at $\Delta E=20 \mathrm{MeV}$ and $\mathrm{L}-0$, In the full threequadratic-surface parametrlzation. 12 
- K.T.R. DAVIES, A.J. SIERK and J.R. NIX

than neck formation $\sigma$. On the other hand, all of the onebody dissipation wodels generate trajectories in which $\sigma$ changes wuch wore rapidly than $x$. The result is that for $\Delta E$ - $20 \mathrm{MeV}$ fusion occurs only for no dissipation and two-body viscosity. For the one-body dissipation models the system strongiy resists compound nucleus formatiol. Table I shows a comparison of the energy thresholds for the four main dissipation models.

We next study the effect of constralning the end bodies to be spherical; 1.e. both the first and third surfazes in the three-quadratic surtice parametrization 12 are forced to be spheres throughout the full dynamical evolution. It is very important to study this approximation since it has been widely used In many other macroscoplc models. 2-4 In F1g. 5 we shuw the trajectorles for the four main types of dissipation at $\Delta E=20 \mathrm{MeV}$. The most dramatis change 18 for twobody Vlscosity, whose trajectory leads to more compressed shapes than the corresponding trajectory when the spherical constraint is not imposed. The third column of Table I 118 ts the threshold $\Delta E$ when the ends are constrained to be

TABLE I Calculated additional ereigy $\Delta E$ relative to the maximum In the ore-dimensional interaction barrier required tc form a compound nucleus in a head-on coll1sion for $110 \mathrm{Pd}+110 \mathrm{Pd}+220 \mathrm{U}$.

\begin{tabular}{lrc}
\hline Type of dissipation & \multicolumn{2}{c}{$\Delta E(\mathrm{MeV})$} \\
\cline { 2 - 3 } & $\begin{array}{c}\text { Full three-quadratic- } \\
\text { surface parametrization }\end{array}$ & $\begin{array}{c}\text { Spherical } \\
\text { ends }\end{array}$ \\
\hline No dissifaticn & $1.5 \pm 0.2$ & $4.5 \pm 0,1$ \\
Two-body v1scosity & $5 \pm 0.5$ & $0.5 \pm 0.5$ \\
Wall formula & $90 \pm 2$ & $60 \pm 2$ \\
Wall and vindow & $99 \pm 0.5$ & $32 \pm 0.5$ \\
\hline
\end{tabular}


DYNAMICAL FUSION THRESHOLDS

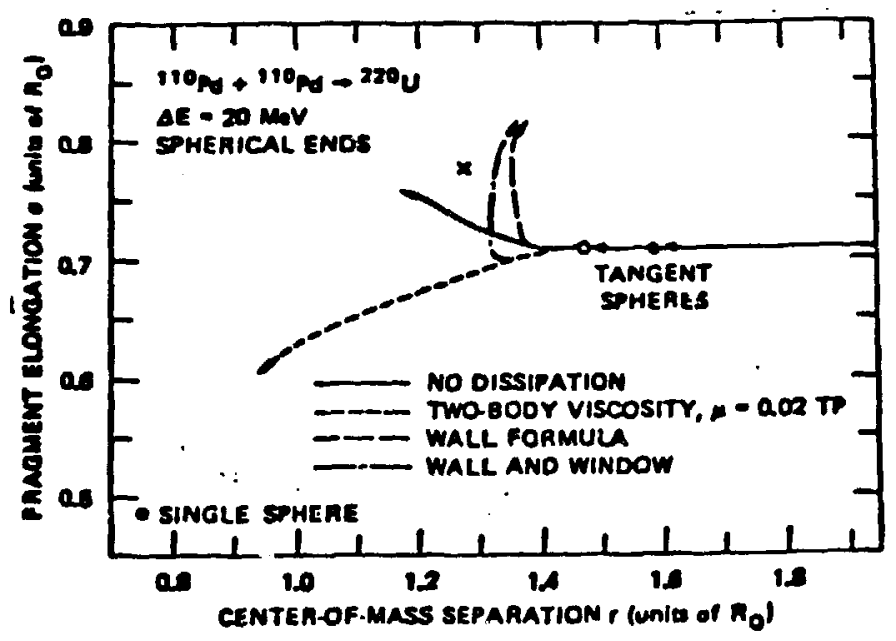

FIGURE 5 Ef fect of dissipation on dynamical trajectories in the $r-0$ plane for the reaction $110 \mathrm{Pd}+110 \mathrm{Pd}$ $\rightarrow 220 \mathrm{~J}$ at $\Delta E=20 \mathrm{MeV}$ and $\mathrm{L}=0$, when the end bodies are constrained to be spherical.

spherical. You see that there can be substantial discrepancies arlsing from the approximation of using spherlcal end bodies. In particular, for the wall formula the additional threshold energy $\triangle E$ is about $30 \mathrm{MeV}$ larger when the spherical constraint is not Imposed.

We now show the effect of changing the charge or angular momeitum of the system. In Fig. 6 we show dynamical trajectorles and saddle polnts for different values of $Z^{2} / A$ of the total system. As the charge on the system increases, the saddle point moves to a more compact configuration while the trajectory is deflected in the opposite direction. Thus it becomes more difficult to satisfy the fusion criterion as the charge on the system increases. Note that for $\mathrm{Z}^{2 / A}=$ 38.7 the trajectory just passes through the saddle point for a very small $\Delta E$ value, so that, for two-body vlscosity, $Z^{2 / A}$ - 38.7 to essentlaj.ly the threshold value.2-4 The effect of angular momentum is qualitatively simllar to that of charge 
K.T.R. DAVIES, A.J. SIERK AND J.R. NIX

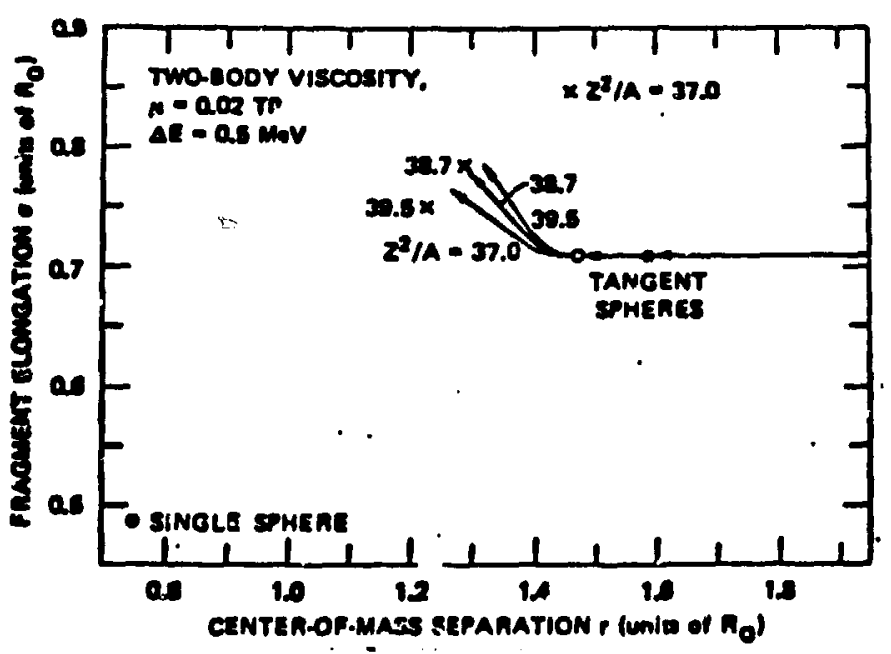

FIGURE 6 Effect of the nuclear system on saddle-point configurations and dynamical trajectorles in the $r-\sigma$ plane for $\Delta E=0.5 \mathrm{MeV}$ and $L=0$, calculated for twobody viscostey. Each saddle point and trafectory is labeled by the value of $Z^{2} / A$ for the combined system, with the symmetri. target and projectile chosen to lie along Green's approximation to the valley of prstablitty. 20

regarding the behevior of saddle polnts and dynamical trajectories, $1^{-4}$ as we show in Fig. 7. We see that it 18 more difficult to achleve fusion as the angular momentum incresses unce the saddle point muves downward and to the left while the dynamical path is shifted tn the right.

We now consider the fissilities, or equivalently the 2 2/A values, which are applicable to different regions of our configuration space. For the entrance channel, in the region near contact, the appropriate $z^{2} / A$ value is given by the expression, $2-4$

$$
\left(Z^{2} / A\right)_{\text {eff }}=\frac{4 Z_{1} Z_{2}}{A_{1}^{1 / 3} A_{2}^{1 / 3}\left(A_{1}^{1 / 3}+A_{2}^{1 / 3}\right)}
$$

However, as the system attains a wore coalesced shape, Eq. 
DYNAMICAL FUSION THRESHOLDS

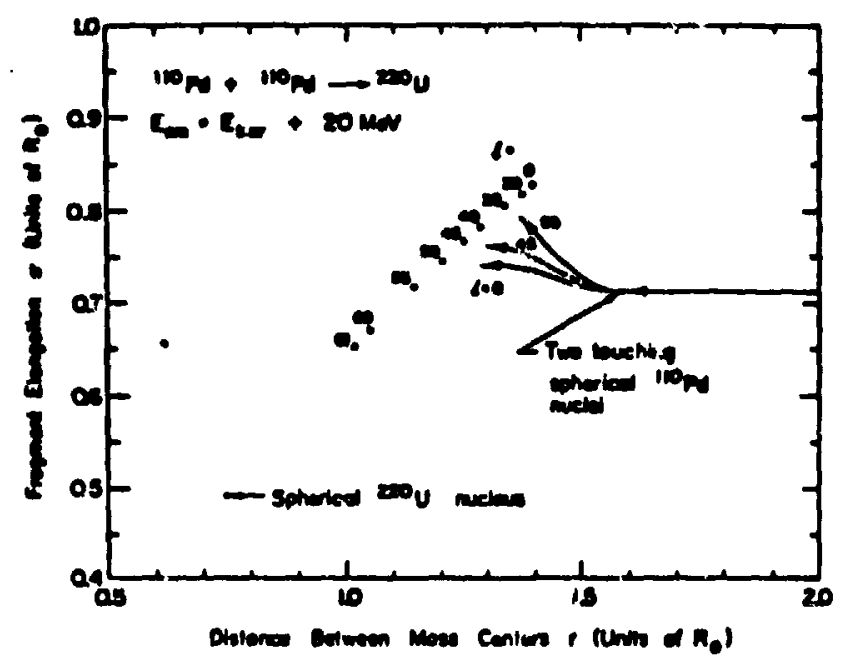

FIGURE 7 Effect of angular momentum on saddle-point configurations and dynamical trajectories in the $r-\sigma$ plane for $\Delta E=20 \mathrm{MeV}$ and zero dissipation. The nuclear acroscopic eneryy is the single-Yukawa modei. 1t Varlous angular momenta label the trajectories and saddle points, with the latter Indicated by circles. The dashed trajectory refers to the critlcal angular momentum $l-45$, above which there is no fusion.

(7) 1s no longer adequats. Instead, in the region near the saddle point, the appropriate $22 / A$ value is that of the cotal aystem. For the entire dynamical fusion process, we have found emplrically that it is conventent to use the geowetricsl man

$$
\left(z^{2 / A}\right)_{\text {mean }}-\left[\left(Z^{2 / A}\right)_{\text {eff }}\left(Z^{2 / A}\right)\right]^{1 / 2}
$$

which gives equal welghting to the entrance-channel and coalesced-ahape values. We note swo that for mass-sjmmetric reactions we have the identity

$$
\left(2^{2 / A}\right)_{\text {eff }}-\left(2^{2 / 1}\right)-\left(2^{2 / A}\right)_{\text {mean }}
$$

In Fig. 8 we compare our calculated resulte 5 with the 
K.T.R. DAVIES, A.J. SIERK and J.R. NIX

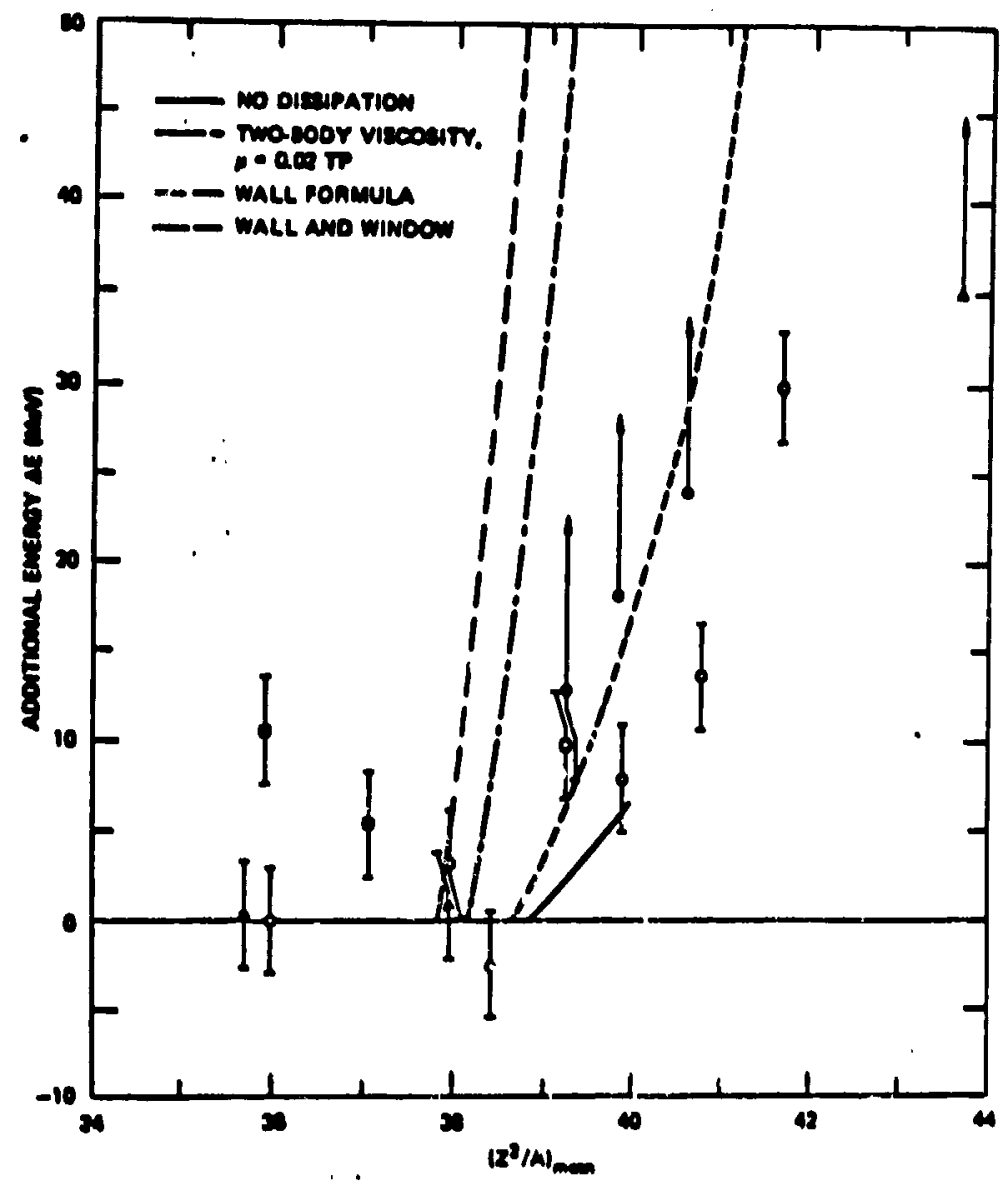

FIGURE 8 Comparison of additional energy cu required for compound-nucleus formation calculated for eymetric -yetems with experimental values for asymetric eyoteme

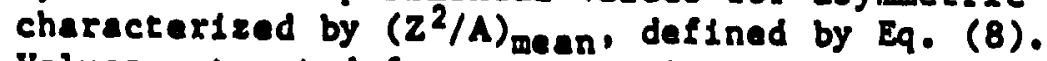

Values extracted from evaporation-rusidue masuremente are represented by colld eymbole, whereas ralues extracted frnm weasuremente of nearly aymetric flesionlike fragmente are reprzsented by open aymols. (See Ref. S for the experimental references.)

experimental data. We plot the calculated threehold $\Delta E$ ve $(2 / A)_{\text {mean }}$ for each of the four maln types of viecostty conelderca. The one-body diesipation resulte are an order of megnitude greater than those for zero dlespation or twobody viscostey. SInce the experimante are for 
DYNAMICAL FUSION THRESHOLDS

mass-asymmetric reactions, we have tried to approximately scale the date to compare with our theoratical results for mass-symmetric reactions. This is accomplished by using the geowetrlc mean $\mathrm{Z} 2 / \mathrm{A}$, defined in Eq. (8). For both the sol1d and open symbols, the experimental values of the additional energy $\Delta E$ are determined by subtiacting from the experimental barrier helghts extrapolated values that co:rectly reproduce the smooth trende for somewhat lighter nuclel. The experimental values appear to be in better agreement with the results for two-body viscosity than with the results for either type of one-body dissipatioll. However, mainly because the error bars on the thre: highest solid symbols extend to +- , any conclusions regarding the nuclear dissipative mechanion wust be regarded we very tentative.

\section{TDHF RESUISS}

We shail now discuss some TDHF resulte which can be interpreted as the microucoplc analogue of the macroscopic extra push. However, we emphasize that the origin of dissipation 18 different is microscoplc tivesties than in any of th macroscopic viscosity models.dl In particular, the TDKr dissipation arises only from one-body collisions with the mean-field potential.

Typical fuelon results for heavy systems are 1llustrated in F1g. 9. These calculations 8.9 were performed for head-on collisione of $86 \mathrm{Kr}+139 \mathrm{La}$. The s.nteraction time 18 plotted ve the laboratory bombarding energy. The 1nteract1on time is defined as the time interval during which the density in the overlap reglon between the coalesced lons exceede one-half the saturation density of nuclear matter. The most atriking feature noticed is that there are two 
X.T.R. DAVIES, A.J. SIERK and J.R. NIX

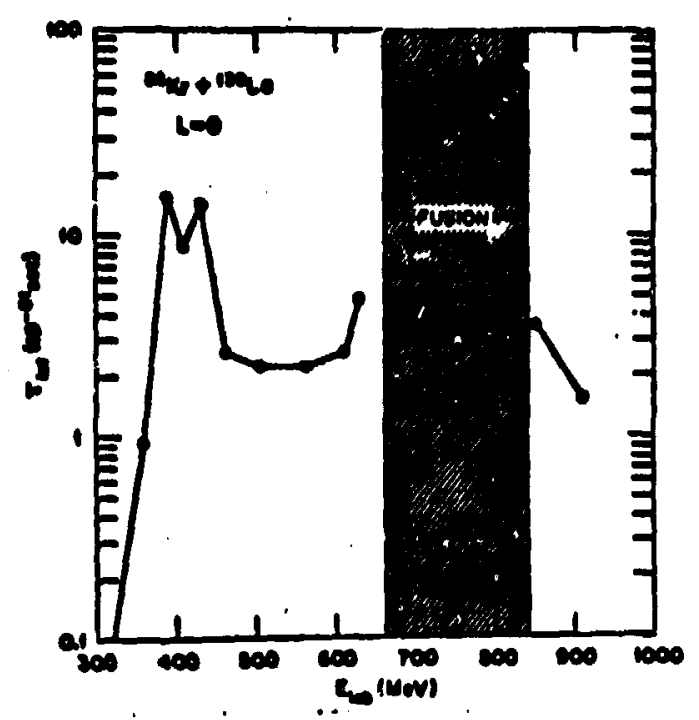

FIGURE 9 The Interaction lime versus the laboratory bombarding energy for head-on coll1sions of ${ }^{86} \mathrm{Kr}+$ $13 \%$. The open circles are the results of the TDluF calculatlons. The shaded area showe the higher-energy fusion region. The calculatione were performed using the Skyrme If interaction.

energy reglons where one flad fusion-like belavior. In the low-energy region near the inceraction barrlar one observes three long-11ved configurations. Then for energles from $\mathrm{E}_{\text {lab }}-660$ to $-840 \mathrm{MV}$ we find true fuslon in the sense that, a fur as we can determine from the calculations, the oyatem never comes apart. The funton threshold at $E_{1 a b}$ $660 \mathrm{MaV} 1$ th the direct analogue of the macroscoplc dynamical fuston threshold discussed in Section 3. Above $E_{1 a b}=840$ MeV, fusion abruptly disappears for head-on collisions; this 1s the angular momentum window, which is a dynamical fuston threshold found only in TDHF studies.

We emphesize too that the long-11ved conflgurations obeerved rear the barrier are not true fusion cases since each eventually undergoes aciseion after $\sim 10-20 \mathrm{sec}$. They do 
DYNAMICAL FUSION THRESHOLDS

not currespond to fast fission 2 either because the final masses and charges of the reaction products are very close to those of tie Incident projectile and target. Since there 18 a fl-ctuating stucture observed in this energy region, one suspects that such a reaction may correspond to some type of long-11ved molecular resonance. Alsc, it is interesting that such fusion-like behavior near the barrier 18 very reminiscent of the adiabatic slither, or cold fusion, fredicted recently by Swlateck1. 3

The higher-energy fusion region is in very poor agrcewent with the experimental results, 21 for which fusion is found at laboratory borinarding energies of 505, 610, and 710 MeV. In the TDHF calculatlous, ${ }^{-}$? Euston does not occur for any angular momentum at the lower two experimental energies, but it does occur for a range of angular momenta at the highest experimental energy ( $710 \mathrm{MV})$.

However, the TDHF fuston behavior is very sensitive to the cholce of the effective two-body interaction. For the studies shown in $\mathbf{1 g}$. 9, the Skyrme II potential was uned. In recent TDHF studies 22 of $86 \mathrm{Kr}+139 \mathrm{La}$, it 1 s found that if one uses the Skyrme III Interaction, the extra-push threshold in Fig. 9 1s decreased to $E_{1 a b} \leq 410 \mathrm{MaV}$. Thts 10 - change of at least $250 \mathrm{MeV}$, wh1ch is a viry large effect I Flgure 10 displays the rias radius of the total aystem as a function of time for these two Skyrme forces.' For the Skyrme II potent1el, the rmo radiue decreases to a minf mum value, after which 1t increases Indefinitely a the ayater receparates. On the other hand, the rme radiue for Skyrme III decreases to a minimum and then increases to a maximum, after which $1 t$ is dramatically damped in a highly coalesced stata. Clearly, additional atudies wth Skyrwe IiI and other forces must be pursued in order to quantify the TDHF 
K.T.R. DAVIES, A.J. SIERK and J.R. NIX *

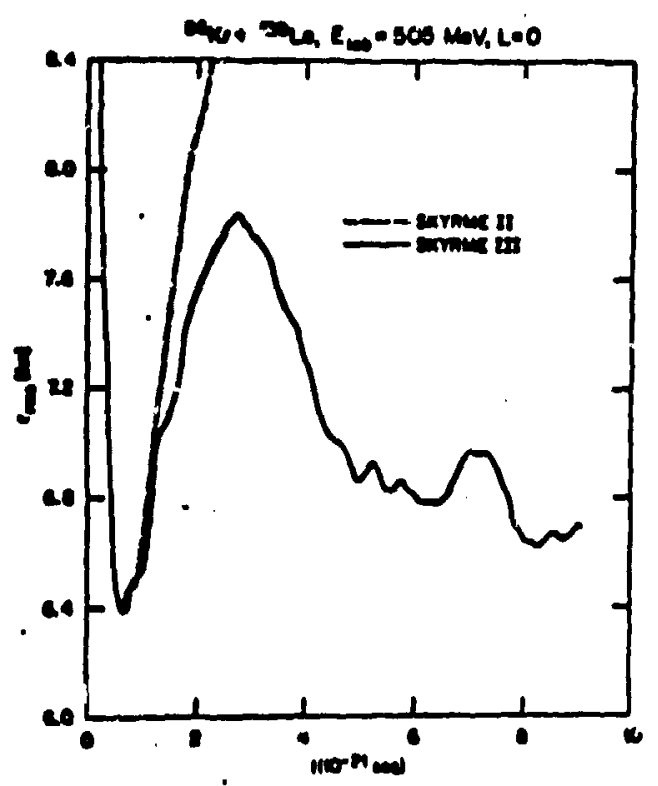

FIGURE 10 The rms radius of the total system as a function of time for head-on collisions of $86 \mathrm{Kr}+139_{\mathrm{La}}$ at $\mathrm{E}_{1 \mathrm{a}} \dot{b}$ - $50 \mathrm{~s} \mathrm{~V}$. The Interactions used are the finite-range Skyrme potentiale.

fusion behsuitor of l savy gystems. In fact, it has recent?, been suggested 11 that the modifled Skyrme M Interaction should be examined eince it gives the correct nuclear compreselbility and reproducus experimental flesion-barrler hasghte.

Table II shows yet another example of the cenoltivity of TDHF fusion bahavior to the affective two-body interaction. TDHF celculations have been performed for head-on coll1elore of $160+160$, In which the thrashold for the relatively high-energy TDHF angular momentum window has been deternined for ariaty of Skyrme forces. 22 The forcn labeled BGK was a very simplifled Skyrme lorce uned in the Bonche, Gramaticos, and Koonin paper.23 For the other Skyrwe forces, the error bars on ihe threshold onergies Indicate the precleion with which the son window has been 
DYNAMICAL FUSION THRESHOLDS

TABLE II TDHF studies of the fuston window for headon coll181one of $160+160$.

\begin{tabular}{lc}
\hline Skyrme force & $\begin{array}{c}\text { Laboratory threshold } \\
\text { energy (In MeV) } \text { for the window }\end{array}$ \\
\hline BGK & 54 \\
II & $62.5 \pm 2.5$ \\
III & $57.5 \pm 2.5$ \\
IV & $42.5 \pm 2.5$ \\
V & $52.5 \pm 2.5$ \\
VI & $52.5 \pm 2.5$ \\
\hline
\end{tabular}

determined. Notice that there are rather large diflerences In the varlous threshold energies, ranging from $42.5 \mathrm{MeV}$ for Skyrme IV to $62.5 \mathrm{MeV}$ for Skyrme II. Mlso, it should be pointed out the experimant of Lazzerini et $\$ 1.24$ was done at a laboratory energy of $68 \mathrm{MeV}$, whlch 18 only 3-8 MeV above the limlts for the Skyrme II threshold. Since the results of these mesurements seemed to rule out the sxistence of the window, it 1s suggested that it might be desirable to do th1. experiment agaln at aowewhet higher encrg\%.

5. SUMMARY

We now summerize the min results. Effects of the extrapush machantsm are predicted by both macroscuplc and microcopic theorles and include the following. Above certain critical flsellity, fusion cannot occur unt1l the bomberding energy reaches a threshold value which 18 greater than the entrance-channel lnteraction barrier helght. In ordar to understand heavy-ion fusion, one wust take into account properties of both the entrance channel and the saddle-polnt regions of configuration spece. Also, the mecroscopic 
K.T.R. DAVIES, A.J. SIKRK and J.R. NIX

results are quite sensitive to some of the detalls of the model. For example, there can be substantial discrepancies between the thresholds calculated with different shape parametriations. However, the main uncertalnty in the acroscoplc work 1s the nature of the dissipation mechanism ance tice resulte for one- and two-body viscosity are cleariy very different. Finally, In the whcroscopic TDHF studies both che extra-push threshold and the angular momentum window seen to be very sensitive to the cholce of the effective two-body Interaction.

\section{REFERENCES}

1. J. R. NIX and A. J. SIERK, Phys. Rev." 15, 2072 (1977).

2. W. J. SWIATECKI, Phye. Sar, 24, 113 (1901).

3. W. J. SWIATECKI, Jucl. Phys. A376, 275 (1982).

4. S. BJÓRNHOLY ane W. J. SWIATECKI, Nucl. Phys. A391, 471 (1982).

5. K. T. R. DAVIFS, A. J. SIEBK, and Jo R. NIX, :o be published in Phys. Rov. This peper containe additional thooreticnl and experimental refarences relevant to dynamical fuelon threaholde.

6. P. BONCHE, K. T. R. WAVIES, 3. FLANUERS, H. FLOCARD, B. GRAMATICOS, S. E. KCONIN, S. J. KRIEGER, and K. S. WEISS, Phys. Rav. C 20, 641 (1979).

7. K. T. R. DAVIES, K. R. S. EEVI, and M. R. STRAYER, Phys. Rev. C 20, 1372 (1979).

8. K. T. R. DAVIES, K. R. S. DEVI, and M. R. STRAYER, Phye. Rev. Lete. 44, 23 (1980).

9. K. T. R. DAVIES, K. R. S, DEVT, and $r$ R. STRAYER, Phys. Rev. C 24, 2576 (1981).

10. H. STOCKER, R. $\chi$. CUSSON, H. J. LUSTIG, A. COBBI, J. HAKW, J. A. MARUHW, and W. GRLINER, Z. Phys. A306, 235 (1982).

11. J. R. NIX, to be published In Crmments on Muclear and Particle Physice.

12. J. R. NIX, Nucl. Phye. Al30, 241 (1969).

13. K. T. R. DAVIES, A. J. SIERK, and J. R. NIX, Phys. Rev. C 13, 2385 (1976).

14. P. MÓlLER and J. R. NIX, Nucl. Phys. A272, 502 (1976). 


\section{DYNAMICAL FUSION THRESHOLDS}

15. H. J. KRAPPE, J. R. NIX, and A. J. SIERK, Phys. Rev. Lett. 42, 213 (1979).

16. H. J. KRAPPE, J. R. MIX, and A. J. SIERK, Phys. Rev. C 20, 992 (1979).

17. A. J. SIERK and J. R. HIX, Phys. Rev, C 21, 922 (1980).

18. J. BEOCKI, Y. BONEH, J. R. NIX, J. RANDRUP, M. ROBEL, A. J. SIERK, and W. J. SWIATECKI, Ann. Phys. (N.Y.) 113,330 (1978).

19. J. RANDRUP anc W. J. SWLATECKI, Ann. Phys. (N.Y.) 125, 193 (1980).

20. A. E. S. GREEN, Nuclear Phys1c8 (McGraw-Hili, New York, 1955), PP. 185, 250 .

21. P. DYER, M. P. WEBB, R. J. PUIGH, R. VANDENBOSCH, T. D. THOMAS, and M. S. ZISMAN, Phys, Rev. C 22, 1509 (1980).

22. K. T, R. DAVIES, J. A. MARUHN, and M. R. STRAYER, to be published.

23. B. BONCHE, B. GRAMMATICOS, and S. E. KJONIN, Phys. Rev. C 17,1700 (1978).

24. A. LAZZARINI, H. DOUBKE, K. T. LESKO, V. METAG, A. SEAMSTER, R. VANDENROSCH, and W. MERRYFIELD, Phy $z$, Rev. C 24,309 (1981). 